\title{
Defining design parameters and criteria for the avoidance of moisture-related problems within current Chilean buildings.
}

\author{
Fernando Sarce $^{\mathrm{a} *}$, Camilo Lanata ${ }^{\mathrm{b}}$, Annesi Giacaman ${ }^{\mathrm{c}}$, Héctor Altamirano-Medina ${ }^{\mathrm{d}}$. \\ a Al-Asala Colleges, Architectural Engineering Department, Dammam, Saudi Arabia. \\ b Ministerio de Vivienda y Urbanismo, Unidad de Habitabilidad y Eficiencia Energética, DITEC, Santiago, Chile. \\ c Universidad de la Frontera, Facultad de Medicina, Centro de Excelencia en Medicina Traslacional, Temuco, Chile. \\ $d$ Insitute for Environmental Design and Engineering, University Collegue London, UK.
}

\begin{abstract}
A preliminary assessment of the new Moisture Assessment Tool (MAT) developed by the Chilean Ministry of Housing and Urbanism (MINVU) was carried out for 36 Provinces along the 9 thermal zones defined for the Chilean territory. Calculations were conducted in accordance with ISO 13788 and the Chilean standard NCh 1973, complemented with the ADF moisture criteria and benchmarked with Passivhaus hygiene

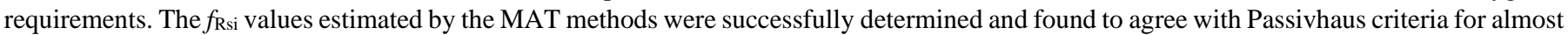
every thermal zone. This research provides theoretical insight to adjust climate-dependent design parameters and criteria to improve the methods and calculations for the avoidance of condensation and mould growth.
\end{abstract}

Peer-review under the responsibility of the organizing committee of the ICMB21.

Keywords: indoor atmospheric moisture; relative humidity; mould growth; water activity; energy building regulations; moisture assessment.

\section{Nomenclature}

$T_{s i} \quad$ Minimum surface temperature

$f_{\text {Rsi }} \quad$ Temperature factor

$\mathrm{p}_{\text {sat }} \quad$ Minimum acceptable vapor pressure of the indoor air

$\varphi_{s i, c r} \quad$ Critical surface relative humidity

$\mathrm{p}_{v} \quad$ Monthly average indoor air partial pressure

\section{Introduction/Background}

According to the last census survey carried out in 2017 by the National Institute of Statics (INE) [1], there are around 4.5 million homes ( $69 \%$ of the current Chilean housing stock) that were built before the introduction of the Thermal Regulation (RT) in 2000, which potentially may not comply with any energy efficiency requirements. The Ministry of Housing and Planning (MINVU) is currently proposing a modification of the General Ordinance of Urban Planning and Constructions (OGUC) that specifies new energy efficiency targets for buildings, thermal zones, and hygiene requirements [2].

Excessive moisture levels in buildings may provide favourable conditions for microbial growth that could affect the health of its occupants [3]. In Chile, there are no official figures about how many homes are truly affected by moisture-related problems such as condensation and mould growth. This situation has generated concern among public institutions, such as MINVU, which has resulted in high public expenditures due to an increased number of complaints from homeowners due to moisture-related problems. For this end, MINVU have developed several standards and guidelines, and it is currently working on a Moisture Assessment Tool (MAT) intending to support the design of building construction solutions to help prevent and avoid condensation risks and mould growth. These have set the framework for legislative requirements for compliance mainly for new buildings, but also have helped to provide the minimum technical requirements for existing buildings (e.g., retrofitting) included in the national Atmospheric Decontamination Plans (PDA) for highly polluted cities with particle matter $\mathrm{PM}_{10}$ and $\mathrm{PM}_{2.5}$.

The methods and calculations used for MAT were developed in accordance with ISO 13788 [4] and adopted through the National Institute of Standardization (INN) as the Chilean standard NCh 1973. The microbial surface criterion, known as the critical surface relative humidity, $\varphi_{s i, c r}$ value, serves to determine a minimum surface temperature $\left(T_{s i}\right)$ and temperature factor $\left(f_{\mathrm{Rsi}}\right)$, for the avoidance of condensation and mould growth. However, due to the newly proposed thermal zones in Chile and thermal transmittance values, there is still no consensus as to a clear definition for which design parameters and criteria should be considered in MAT. Therefore, the aim of this research is to preliminary assess a set of design parameters and criteria to be used as part of the current proposed MAT, by adopting international state-of-the-art criteria to further improve the design of building construction solutions for the avoidance of condensation and mould growth of the new and existing Chilean housing stock.

\footnotetext{
* Corresponding author. +56 95241 9331. fernando.sarce@ alasala.edu.sa
} 


\subsection{Methodology}

MINVU has alphabetically divided the country into 9 thermal zones (A, B, C, ..I) and categorized them among the 53 Chilean Provinces. From these Provinces, 36 were selected which transversally represents each thermal zone from the North to the South, and from the East to the West. The design parameters to estimate the minimum acceptable vapor pressure of the indoor air, $\mathrm{p}_{\text {sat }}$ and the minimum surface temperature $\left(T_{s i}\right)$ were calculated using one monthly average indoor air partial pressure, $\mathrm{p}_{v}(1,427 \mathrm{~Pa})$ and the critical surface relative humidity, $\varphi_{s i, c}=0.8$ as a function of the outdoor minimum mean air temperature, $T_{e}$ according to the defined procedures in MAT. From this, the unknown temperature factor $\left(f_{\mathrm{Rsi}}\right)$ was determined for each Province and thermal zone according to the design procedure currently established in NCh 1973. Additionally, the monthly critical surface relative humidity, $\varphi_{s i, c r}$ was used from the Approved Document $\mathrm{F}\left(\varphi_{s i, c r}=0.75\right)$ [5], and current Passivhaus $f_{\mathrm{Rsi}}$ values were set as a benchmarking to compare the previous calculations. Data analysis was performed using Prism (GraphPad Prism9.0).

\subsection{Results}

Figure 1(a) shows the calculated $f_{\mathrm{Rsi}}$ values for the 36 selected Provinces along the 9 thermal zones within the Chilean territory. The red dotted line represents current methods and calculations used for MAT in accordance to ISO 13788, and the blue dotted line use the $\varphi_{s i, c r}$ from the Approved Document F. The black dotted line represents the Passivhaus benchmark. Figure 1(b) shows

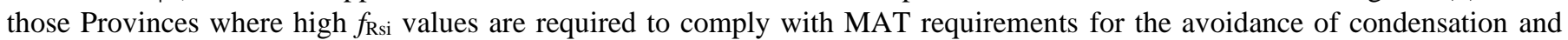
mould growth.
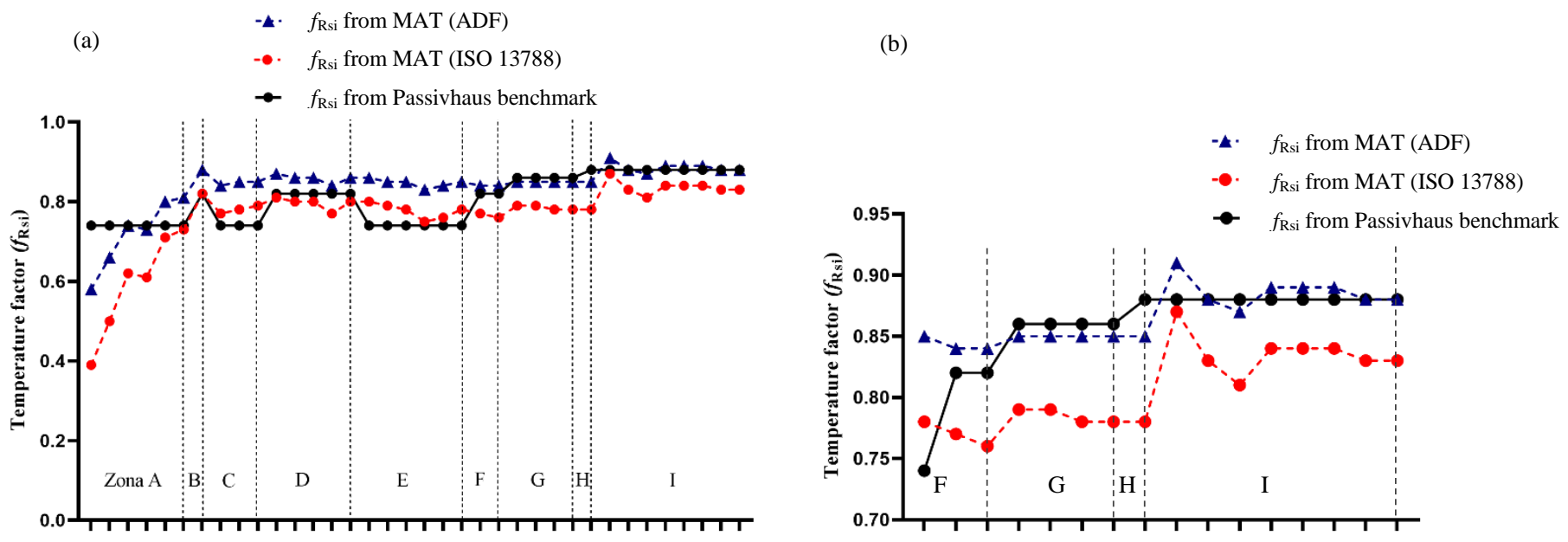

Figure 1. (a) $f_{\text {Rsi }}$ calculations for the selected 36 Provinces within the 9 Chilean thermal zones. (b) $f_{\text {Rsi }}$ values in severe weather conditions.

\subsection{Discussion and conclusions}

The preliminary $f_{\text {Rsi }}$ values estimated by the MAT methods (see Figure 1), show a clear agreement when compared with the Passivhaus hygiene criteria for the avoidance of mould growth. These results also confirm the influence of the design outdoor temperature for each thermal zone, as in the case of warmest thermal zone $\mathrm{A}$, with the lowest $f_{\mathrm{Rsi}}$ value. In most critical cases (thermal zones F to I shown in Figure 1(b)), where MINVU has established the most severe weather conditions used within MAT, high $f_{\text {Rsi }}$ values were determined. When adopting the surface criteria from the AD-F, almost every $f_{\text {Rsi }}$ value for all thermal zones match those that comply with Passivhaus hygiene criteria for the avoidance of mould growth. Overall, the main implications of this research are that it serves as a framework for further optimization of the current MAT state, and it provides a theoretical benchmark to further explore the definition of climate-dependent design parameters and criteria. This means that new climate adjustments on the proposed thermal zones could be considered in MAT to further improve the methods and calculations for the avoidance of condensation and mould growth.

\section{References}

[1] Instituto Nacional de Estadísticas. (2018). Census Survey: Chilean housing stock. Santiago.

[2] Ministerio de Vivienda y Urbanismo. (2020). Ordenanza General de Urbanismo y Construcciones. Santiago.

[3] Peat JK, Dickerson J and Li J (1998). Effects of damp and mould in the home on respiratory health: a review of the literature. Allergy, 53, $120-128$.

[4] ISO 13788: 2012. (2012) Hygrothermal performance of building components and building elements-Internal surface temperature to avoid critical surface humidity and interstitial condensation-Calculation methods. Brussels.

[5] Approved Document F - Ventilation. (2010). In: Government DfCaL, (ed.). London. 